\title{
Profissionais de Enfermagem na UTI e seu protagonismo na pandemia: Legados da Covid-19
}

\author{
Nursing professionals in the ICU and their role in \\ the pandemic: Legacies of Covid-19
}

\author{
Jaqueline Fernandes Ribeiro ${ }^{1}$ (1) \\ Josefa Mayara de Figueiredo Andrade 2 (1) \\ Krysnah Allen da Silva Melo 3 (1)
}

\author{
Francisca Lianne Fernandes Bandeira 4 (1) \\ Pollyanna Sousa da Silva ${ }^{5}$ (1) \\ Maria Artunilda Bezerra Pinho ${ }^{6}$ (1)
}

${ }^{1}$ Autora para correspondência. Faculdade Santa Maria (Cajazeiras). Paraiba, Brasil. jaqfribeiro@hotmail.com 2-6 Faculdade Santa Maria (Cajazeiras).Paraíba, Brasil. mayarafiqueredo@hotmail.com, krysnah_allen@hotmail.com, artunilda@gmail.com, enfpollyannasousa@gmail.com, liannefbandeira@hotmail.com

\begin{abstract}
RESUMO | OBJETIVO: Analisar a atuação dos profissionais de enfermagem na Unidade de Terapia Intensiva, considerando seu protagonismo no atendimento aos pacientes com COVID-19 e os legados dessa pandemia até o momento. MÉTODO: Revisão sistemática com base no protocolo Preferred Reporting Itens for Systematic Reviews and Meta-Analysis. Foram consideradas publicações em português, inglês e espanhol dos últimos dois anos (2019-2020) indexados na Biblioteca Virtual do Ministério da Saúde do Brasil, na PubMed, Cochrane Central e Web of Science. RESULTADOS: Foram selecionados 14 artigos para a análise dos dados. A atuação do profissional de enfermagem no combate ao COVID-19 é consenso em diferentes países, sendo destacada sua atuação como linha de frente e as necessidades de adaptação a um contexto inédito, lidando com o desconhecido e com pesquisas frequentes que apontavam novas descobertas. Como implicações futuras frente à atual pandemia verificou-se fatores como maior valorização dos profissionais de enfermagem, inclusive com uso de profissionais intensivistas e anestesistas, diversificação das formas de comunicação, melhor autogerenciamento e gerenciamento das equipes e o teleatendimento em cuidados de enfermagem. CONCLUSÃO: A pandemia trazida pela COVID-19 evidenciou o protagonismo dos enfermeiros. Com as mudanças e adaptações exigindo novos protocolos e formas de atendimento, podendo ser considerados como legados.
\end{abstract}

DESCRITORES: Infecções por Coronavirus. Unidades de Terapia Intensiva. Enfermeiras e Enfermeiros. Papel do Profissional de Enfermagem. Pandemias.

\begin{abstract}
OBJECTIVE: To analyze the performance of nursing professionals in the Intensive Care Unit, considering their role in assisting patients with COVID-19 and the legacies of this pandemic so far. METHOD: Systematic review based on the Preferred Reporting Items for Systematic Reviews and Meta-Analysis protocol. Publications in Portuguese, English, and Spanish from the last 2 years (2019-2020) were considered, indexed in the Biblioteca Virtual do Ministério da Saúde of Brazil, PubMed, Cochrane Central, and Web Of Science. RESULTS: 14 articles were selected for data analysis. The role of nursing professionals in combating COVID-19 is a consensus in different countries with emphasis on their role as the front line and the need to adapt to an unprecedented context, dealing with the unknown and with frequent research that pointed to new discoveries. As future implications in the face of the current pandemic, factors such as greater appreciation of nursing professionals, including the use of intensive care professionals and anesthesiologists, diversification of forms of communication, better self-management and management of teams, and telecare in nursing care were found. CONCLUSION: The pandemic brought by COVID-19 highlighted the role of nurses. With changes and adaptations requiring new protocols and forms of assistance, they can be considered legacies.
\end{abstract}

DESCRIPTORS: Coronavirus infections. Intensive Care Units. Nurses. Nurse's Role. Pandemics. 


\section{Introdução}

O novo coronavírus (assim chamado pelo seu perfil na microscopia eletrônica em formato de coroa) foi identificado e notificado na China em 2019, provocando a doença que recebeu o nome técnico de COVID-19 e cuja cronologia demonstra uma velocidade impressionante de se disseminar. Isso levou a Organização Mundial da Saúde (OMS) a decretar situação de emergência internacional da saúde pública desde janeiro de 2020, demandando atenção e ações imediatas dos países pelo mundo. A transmissão já decretada como comunitária confirmou o modo agressivo de disseminação onde já não se consegue rastrear as cadeias de infecção desde sua origem. Nesse mês de agosto de 2020, já passa de 23 milhões de infectados e 813.000 mortes em todo o mundo, conforme dados da OMS 1 .

Nesse cenário, o presente projeto propõe um estudo acerca da atuação dos profissionais de Enfermagem na Unidade de Terapia Intensiva (UTI), considerando seu protagonismo no atendimento aos pacientes com COVID-19 e os legados dessa pandemia até o momento. Aprendizados, equipamentos, novos protocolos, enfim, o que ficou que pode ser levado para a melhoria de suas funções.

Entre os profissionais de saúde, o clima é de total atenção e apreensão. A necessidade de enfrentar um cenário totalmente desconhecido em termos de velocidade de propagação, possibilidade de infecção numa escala nunca antes vista e número de mortes só comparáveis a um cenário de guerra. Esse cenário exige dos profissionais da saúde que estão e estarão na linha de frente muito esforço físico e emocional, somado ao estresse e ao alto risco de contrair o vírus $^{2}$. Os profissionais de enfermagem compõem um dos grupos de vulnerabilidade, já que o número de mortos entre profissionais da saúde já é fato e causa preocupação para as autoridades ${ }^{3}$.

Na pesquisa realizada por Bitencourt et al. ${ }^{4}$, o protagonismo dos profissionais de enfermagem foi apontado em todas as interfaces do atendimento aos pacientes com COVID-19 desde a composição das comissões, perpassando pelo planejamento e funcionamento da estrutura física, gestão de recursos humanos e construção de protocolos e fluxos de cuidado, além de atuar diretamente na assistência.
A posição de linha de frente dos profissionais de Enfermagem no ambiente de UTI torna propício esse protagonismo pelas próprias características da profissão que requerem que eles permaneçam por mais tempo ao lado dos pacientes. Dessa forma, como bem afirmam Barbosa et al. $\underline{5}$, as competências desses profissionais se destacam na aplicação de protocolos do Ministério da Saúde relacionados à pandemia. Assim, o interesse no assunto surgiu para que se pudesse melhor entender sobre a atuação desses profissionais na UTI nesse panorama de crise.

Dessa forma, o estudo proposto é relevante socialmente, considerando que trata de uma classe profissional linha de frente na prevenção e combate ao coronavírus, fazendo-se importante conhecer a dinâmica do seu trabalho nesse período de pandemia e as perspectivas futuras desses profissionais, como, por exemplo, os novos aprendizados e formas de trabalho que foram absorvidos pela profissão em decorrência da crise. Salienta-se que o estudo possui relevância acadêmica, considerando que se trata de um assunto novo, um período que pode ser considerado inédito, ainda em curso, que precisa de estudos nas mais diferentes esferas da sociedade e da economia.

Nesse contexto, o presente estudo tem como objetivo analisar a atuação dos profissionais de Enfermagem na Unidade de Terapia Intensiva (UTI), por seu protagonismo no atendimento aos pacientes com COVID-19 e os legados dessa pandemia até o momento.

\section{Método}

Esta revisão sistemática foi planejada de forma a contemplar o protocolo proposto pelo Preferred Reporting Itens for Systematic Reviews and Meta-Analysis 6 . Nesta revisão, procurou-se identificar artigos que exploram a atuação dos profissionais de Enfermagem nas UTI e seu protagonismo durante a pandemia Covid-19, considerando a qualidade das pesquisas realizadas. Dessa forma, o estudo foi direcionado pelo seguinte questionamento: "Quais os legados deixados pela pandemia Covid-19 para a atuação dos profissionais de Enfermagem na Unidade de Terapia Intensiva (UTI)?", que foi elaborado a partir da descrição da PECOS (Quadro 1). 
Quadro 1. Descrição da estratégia PECOS para a elaboração da questão norteadora da revisão

\begin{tabular}{|l|l|l|}
\hline \multicolumn{1}{|c|}{ Acrônimo } & \multicolumn{2}{|c|}{ Descrição } \\
\hline $\begin{array}{l}\text { P (Paciente/ } \\
\text { População) }\end{array}$ & Profissionais de Enfermagem & $\begin{array}{l}\text { Foram incluídos estudos que envolvessem } \\
\text { profissionais de Enfermagem }\end{array}$ \\
\hline E (Exposição) & $\begin{array}{l}\text { Atuação na UTI com pacientes com } \\
\text { Covid-19 }\end{array}$ & $\begin{array}{l}\text { A exposição de interesse foi a atuação desses } \\
\text { profissionais enquanto linha de frente na UTI no } \\
\text { atendimento a pacientes com Covid-19. }\end{array}$ \\
\hline C (Comparação) & Sem grupo de comparação. & $\begin{array}{l}\text { Nesta revisão não foram realizadas comparanes entre } \\
\text { grupos. }\end{array}$ \\
\hline $\begin{array}{l}\text { O (Out comes } \\
\text { (desfecho/ } \\
\text { resultados)) }\end{array}$ & Legados profissionais & $\begin{array}{l}\text { Os principais resultados considerados são os legados } \\
\text { deixados para a atuação profissional de enfermeiros e } \\
\text { enfermeiras na UTI com pacientes com insuficiência } \\
\text { respiratória e alto índice de contágio. }\end{array}$ \\
\hline $\begin{array}{l}\text { S (Study type; } \\
\text { (tipo de estudo)) }\end{array}$ & $\begin{array}{l}\text { Estudos observacionais } \\
\text { transversais, clínicos, de campo e } \\
\text { de caso }\end{array}$ & $\begin{array}{l}\text { Somente foram excluidos estudos teóricos e de } \\
\text { revisão. }\end{array}$ \\
\hline
\end{tabular}

Fonte: Elaborado pelos autores.

O levantamento dos artigos foi realizado nas bases de dados bases de dados da Biblioteca Virtual do Ministério da Saúde do Brasil (BVMS) e na PubMed (US National Library of Medicine), entre os meses de agosto e setembro de 2020, sendo consideradas publicações em língua portuguesa, inglesa e espanhola dos últimos 2 anos (20192020). Salienta-se que o curto recorte temporal selecionado se dar pela pandemia em estudo ter iniciado no ano de 2019 e ainda estar em curso, o que limita o levantamento a esse período.

Para definir as estratégias de busca foram identificadas as palavras-chave "Infecções por Coronavirus"; “Unidades de Terapia Intensiva"; "Enfermeiras e Enfermeiros"; "Papel do Profissional de Enfermagem". "Pandemias", em seguida, por meio do Medical Subject Headings (MESH) no PubMed, foram identificados descritores, também baseado na estratégia PECOS, que pudessem resgatar o maior número de artigos. Os entry terms também foram considerados para composição da estratégia de busca. Após elaborada a estratégia de busca no PubMed, ela foi utilizada nas seguintes bases: Cochrane Central e Web Of Science (WOS). Para busca na base de dados LILACS, os descritores controlados foram identificados por meio da ferramenta Descritores em Ciências da Saúde (DECS). A saturação da literatura foi garantida por meio da análise de listas de referência de estudos incluídos ou revisões relevantes identificadas por meio de pesquisa manual.

Nenhum dos autores da revisão foi cego aos títulos das revistas ou nomes dos autores ou das instituições dos estudos. Foi desenvolvido um diagrama de fluxo (modelo PRISMA) que contém medidas como Identificação, Triagem, Elegibilidade e Inclusão de itens com quantidades e uma declaração explicativa dos motivos de exclusão dos artigos.

Os revisores resolveram as discordâncias por meio de discussão e consenso. Alguns autores foram contatados por e-mail para solicitar artigos completos que não estavam disponíveis na internet gratuitamente, obtendo retorno positivo, com o envio do artigo completo. Para avaliar o risco de viés nos artigos selecionados foi utilizado o instrumento JBI Critical Appraisal Checklist For Studies Reporting Prevalence Data ${ }^{7}$ (Figura 1), o qual evidencia a avaliação dos quatro possíveis tipos de viés, a saber: viés de seleção, de desempenho, de detecção e de atrito. 
Figura 1. Checklist - Relatórios preferidos para revisões sistemáticas e meta-análises: a declaração PRISMA.

JBI Critical Appraisal Checklist for Studies Reporting Prevalence Data

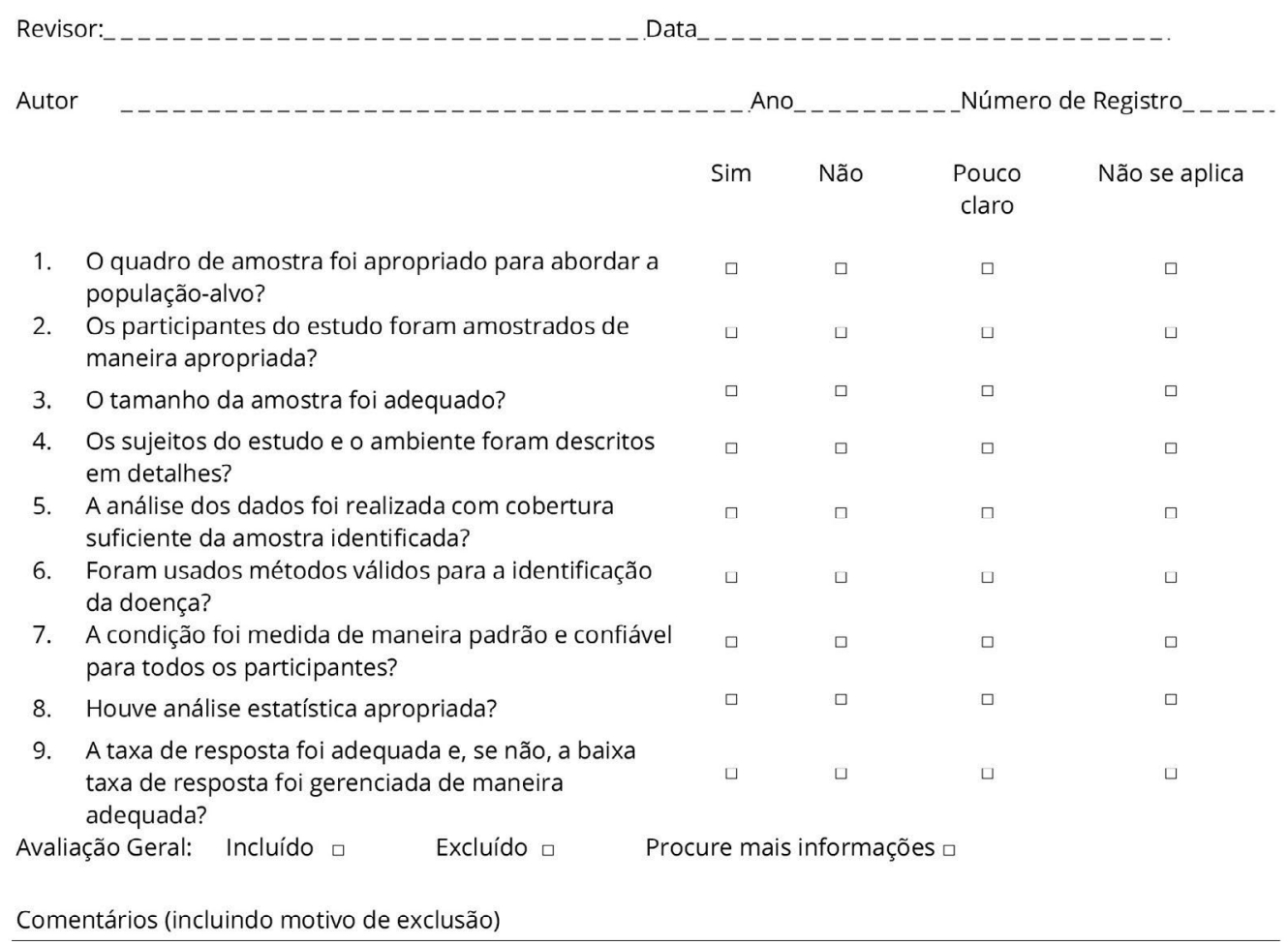

\section{Resultados e discussão}

Após a leitura dos artigos verificou-se que os estudos são muito heterogêneos, o que dificultou a realização de meta-análise. Foi elaborada uma síntese narrativa sistemática com informações apresentadas no texto e um quadro para resumir e explicar as características e os resultados dos artigos incluídos. Para que melhor entendimento dos motivos de exclusão dos artigos foi construído um fluxograma que resume o caminho seguido na inclusão e exclusão dos artigos (Figura 2).

Explica-se, assim, que a busca inicial encontrou como resultados somando todas as bases de dados 2.291 artigos, sendo que 02 foram encontrados por busca manual, 32 artigos apresentaram duplicidade, permanecendo 366 artigos para a etapa seguinte, que foi a leitura dos títulos e resumos. Nessa ocasião, 23 artigos foram considerados elegíveis, todavia, 9 não estavam disponíveis em formato completo, restando 14 artigos para a análise dos dados.

As características dos artigos incluídos estão apresentadas no quadro 2. Ao analisar o tipo de pesquisa dos artigos foi possível verificar prevalência de relatos de experiência. Dos 14 artigos selecionados, somente $3(21,43 \%)$ realizaram estudos exploratórios, com profissionais de enfermagem como participantes de sua pesquisa, todos os três foram realizados no Brasil, com entrevista ou aplicação de questionário realizado via aplicativo de mensagens (WhatsApp). A prevalência de relatos de experiência provavelmente pode ser explicada pela dificuldade na realização de pesquisas nos hospitais, visto o isolamento social necessário no combate à disseminação do vírus. 
Quadro 2. Síntese descritiva dos estudos incluídos (continua)

\begin{tabular}{|c|c|c|c|c|}
\hline \multirow{2}{*}{$\begin{array}{l}\text { Autor/ Ano / Tipo de } \\
\text { estudo / Revista / Pais } \\
\text { / Palavras-Chave }\end{array}$} & \multicolumn{4}{|c|}{ Resultados } \\
\hline & $\begin{array}{l}\text { Metodologia (Amostra, tipo de estudo e } \\
\text { instrumento utilizado) }\end{array}$ & Papel da enfermagem & Desafios enfrentados & $\begin{array}{l}\text { Implicações para as práticas de } \\
\text { Enfermagem }\end{array}$ \\
\hline $\begin{array}{l}\text { Huang et al. (2020) } \\
\text { Qualitativo } \\
\text { International Nursing } \\
\text { Review } \\
\text { Taiwan } \\
\text { COVID-19, Saúde } \\
\text { Global, Enfermagem, } \\
\text { Liderança em } \\
\text { Enfermagem, Papel dos } \\
\text { Enfermeiros, Pandemia, } \\
\text { Equipamentos de } \\
\text { Proteção Individual, } \\
\text { Taiwan }\end{array}$ & $\begin{array}{l}\text { Relato de experiência, descritivo, } \\
\text { documental }\end{array}$ & $\begin{array}{l}\text { A Associação de Enfermeiras de Taiwan } \\
\text { e outras associações de enfermeiras } \\
\text { desempenham um papel de liderança vital } \\
\text { na defesa das enfermeiras, aumentando } \\
\text { a consciência pública, melhorando o } \\
\text { perfil profissional da enfermagem e } \\
\text { compartilhando experiências por meio de } \\
\text { plataformas nacionais e internacionais. }\end{array}$ & $\begin{array}{l}\text { Fornecer equipamento de proteção } \\
\text { individual adequado e pessoal seguro } \\
\text { deve ser a maior prioridade para governos } \\
\text { e formuladores de políticas em todo o } \\
\text { mundo para combater a pandemia com } \\
\text { sucesso. }\end{array}$ & $\begin{array}{l}\text { As implicações para as políticas de } \\
\text { enfermagem e saúde são que precisamos } \\
\text { nos preparar bem para qualquer } \\
\text { pandemia emergente imprevisível no } \\
\text { futuro. }\end{array}$ \\
\hline $\begin{array}{l}\text { McDonald (2020) } \\
\text { Qualitativo } \\
\text { International Nursing } \\
\text { Review } \\
\text { Suiça } \\
\text { COVID-19, Política } \\
\text { de saúde, História, } \\
\text { Controle de infecção, } \\
\text { Liderança, Política } \\
\text { de enfermagem, } \\
\text { Enfermagem, Pandemia, } \\
\text { Revisão de política. }\end{array}$ & $\begin{array}{l}\text { Relato de experiência, descritivo, } \\
\text { documental }\end{array}$ & $\begin{array}{l}\text { Em todos os surtos ao longo da história, } \\
\text { os enfermeiros responderam aos } \\
\text { perigos que o envolvimento direto com } \\
\text { essas crises acarreta. Os enfermeiros } \\
\text { que respondem às populações em } \\
\text { crise aprenderam a não depender } \\
\text { excessivamente daqueles que ocupam } \\
\text { posições de liderança para obter recursos } \\
\text { e proteção da linha de frente ou mesmo } \\
\text { avisos antecipados ou divulgação aberta } \\
\text { sobre o risco de contágio, números de } \\
\text { casos e resultados. }\end{array}$ & $\begin{array}{l}\text { O apoio governamental e social para } \\
\text { pessoas privadas de direitos civis pela } \\
\text { pandemia precisará ser eficaz para manter } \\
\text { a harmonia social, lei e ordem civil. Os } \\
\text { enfermeiros devem estar cientes dessas } \\
\text { tendências em suas comunidades e ser } \\
\text { capazes de garantir que suprimentos de } \\
\text { equipamentos essenciais, medicamentos } \\
\text { e pessoal estejam disponíveis. Garantir } \\
\text { que a enfermagem seja acessível às } \\
\text { comunidades carentes é um esforço } \\
\text { político que algumas enfermeiras podem } \\
\text { precisar iniciar. }\end{array}$ & $\begin{array}{l}\text { A credibilidade da pesquisa é crucial ao } \\
\text { se envolver com líderes políticos que } \\
\text { dependem de especialistas para obter } \\
\text { informações confiáveis sobre as quais } \\
\text { políticas podem ser desenvolvidas e obter } \\
\text { recursos. As informações devem ser } \\
\text { concisas e claras sobre o que é conhecido } \\
\text { e o que é incerto e como isso mudará } \\
\text { com o tempo; Cadeias de suprimentos } \\
\text { para equipamentos essenciais para } \\
\text { surtos futuros são de interesse para os } \\
\text { enfermeiros e precisarão ser controlados } \\
\text { por eles para estarem disponíveis } \\
\text { para surtos futuros. Os enfermeiros } \\
\text { também precisarão revisar os modelos } \\
\text { de pessoal para permitir que até } 50 \% \\
\text { dos enfermeiros fiquem isolados ou em } \\
\text { quarentena na maior parte do tempo. }\end{array}$ \\
\hline
\end{tabular}


Quadro 2. Síntese descritiva dos estudos incluídos (continuação)

\begin{tabular}{|c|c|c|c|c|}
\hline \multirow{2}{*}{$\begin{array}{l}\text { Autor/ Ano / Tipo de } \\
\text { estudo / Revista / Pais } \\
\text { / Palavras-Chave }\end{array}$} & \multicolumn{4}{|c|}{ Resultados } \\
\hline & $\begin{array}{l}\text { Metodologia (Amostra, tipo de estudo e } \\
\text { instrumento utilizado) }\end{array}$ & Papel da enfermagem & Desafios enfrentados & $\begin{array}{c}\text { Implicações para as práticas de } \\
\text { Enfermagem }\end{array}$ \\
\hline $\begin{array}{l}\text { Nascimento, Hattori e } \\
\text { Terças-Trettel (2020) } \\
\text { Qualitativo } \\
\text { Humanidades Médicas } \\
\text { Brasil } \\
\text { Enfermagem; } \\
\text { Saúde Ocupacional; } \\
\text { Coronavírus. }\end{array}$ & $\begin{array}{l}\text { Estudo exploratório } \\
25 \text { enfermeiras de diferentes instituições } \\
\text { de saúde } \\
\text { Questionário aplicado via WhatsApp }\end{array}$ & - & $\begin{array}{l}\text { As dificuldades e medos apresentados } \\
\text { estavam relacionados ao risco diário de } \\
\text { exposição ao vírus, problemas de acesso } \\
\text { e uso de equipamentos de proteção } \\
\text { individual, dúvidas no diagnóstico } \\
\text { diferencial bem como a sobrecarga de } \\
\text { trabalho e o aumento da demanda por } \\
\text { atendimento de pacientes e familiares. }\end{array}$ & - \\
\hline $\begin{array}{l}\text { Nascimento, Hattori e } \\
\text { Terças-Trettel (2020) } \\
\text { Qualitativo } \\
\text { Enfermagem em Foco } \\
\text { Brasil } \\
\text { Pandemias; } \\
\text { Coronavirus; Pessoal } \\
\text { de Saúde; Carência } \\
\text { Psicossocial. }\end{array}$ & $\begin{array}{l}\text { Estudo exploratório } \\
22 \text { enfermeiros } \\
\text { Enviado através do aplicativo WhatsApp } \\
\text { uma questão norteadora: “Quais suas } \\
\text { necessidades pessoais, nesse momento } \\
\text { de pandemia da COVID-19". }\end{array}$ & $\begin{array}{l}\text { Profissionais de linha de frente que } \\
\text { precisaram enfrentar isolamento social } \\
\text { de sua família dada a natureza de seu } \\
\text { trabalho. }\end{array}$ & $\begin{array}{l}\text { As necessidades pessoais dos Enfermeiros } \\
\text { refletem o impacto das medidas } \\
\text { protetivas recomendadas durante a } \\
\text { pandemia da COVID-19 tanto no contexto } \\
\text { laboral como familiar. }\end{array}$ & $\begin{array}{l}\text { Maior demanda para o } \\
\text { autogerenciamento do profissional; }\end{array}$ \\
\hline $\begin{array}{l}\text { Silva et al. (2020) } \\
\text { Qualitativo } \\
\text { Enfermagem em Foco } \\
\text { Brasil } \\
\text { Enfermagem; } \\
\text { Pandemia; Infeccoes } \\
\text { por Coronavirus. }\end{array}$ & $\begin{array}{l}\text { Relato de experiência } \\
\text { Estudo descritivo }\end{array}$ & $\begin{array}{l}\text { Os profissionais da Enfermagem têm se } \\
\text { destacado por atuarem na linha de frente } \\
\text { a prevenção e ao combate da doença, } \\
\text { buscando mitigação da pandemia. } \\
\text { Diante da ausência de uma vacina e } \\
\text { medicamentos antivirais específicos, os } \\
\text { ensinamentos de Florence Nightingale } \\
\text { nunca estiveram tão atuais. Medidas } \\
\text { como a lavagem das mãos, a limpeza dos } \\
\text { hospitais e dos ambientes domésticos, } \\
\text { e a implementação de boletins } \\
\text { epidemiológicos como medidas de } \\
\text { acompanhamento da doença e da curva } \\
\text { epidêmica, tornaram-se imprescindíveis } \\
\text { para o combate desta doença. }\end{array}$ & $\begin{array}{l}\text { Condições de trabalho, o adoecimento } \\
\text { e a morte daqueles que enfrentam com } \\
\text { honradez a pandemia e as consequências } \\
\text { destas em suas vidas profissionais e } \\
\text { pessoais. }\end{array}$ & - \\
\hline
\end{tabular}


Quadro 2. Síntese descritiva dos estudos incluídos (continuação)

\begin{tabular}{|c|c|c|c|c|}
\hline \multirow{2}{*}{$\begin{array}{l}\text { Autor/ Ano / Tipo de } \\
\text { estudo / Revista / Pais } \\
\text { / Palavras-Chave }\end{array}$} & \multicolumn{4}{|c|}{ Resultados } \\
\hline & $\begin{array}{c}\text { Metodologia (Amostra, tipo de estudo e } \\
\text { instrumento utilizado) }\end{array}$ & Papel da enfermagem & Desafios enfrentados & $\begin{array}{c}\text { Implicações para as práticas de } \\
\text { Enfermagem }\end{array}$ \\
\hline $\begin{array}{l}\text { Rodrigues et al. (2020) } \\
\text { Qualitativo } \\
\text { Journal of nursing and } \\
\text { health } \\
\text { Brasil } \\
\text { Saúde do trabalhador; } \\
\text { Profissionais de } \\
\text { enfermagem; Riscos } \\
\text { ocupacionais; } \\
\text { Pandemias; Infecções } \\
\text { por coronavirus. }\end{array}$ & $\begin{array}{l}\text { Relato de experiência } \\
\text { Estudo descritivo }\end{array}$ & - & $\begin{array}{l}\text { A adaptação dos profissionais } \\
\text { assistenciais frente às drásticas mudanças } \\
\text { em seu âmbito de trabalho pode ser } \\
\text { vista como um dos principais desafios } \\
\text { apresentados frente a esta pandemia. } \\
\text { Ações como, atendimento ao paciente } \\
\text { suspeito ou confirmado, carga horária } \\
\text { de trabalho, paramentação, uso correto } \\
\text { dos EPI e aumento da complexidade } \\
\text { assistencial, vêm se mostrando como } \\
\text { grandes preocupações. }\end{array}$ & $\begin{array}{l}\text { Criação de protocolos de saúde } \\
\text { adaptando às necessidades de isolamento } \\
\text { para contenção do vírus, assim como a } \\
\text { proteção dos profissionais e segurança } \\
\text { dos pacientes. }\end{array}$ \\
\hline $\begin{array}{l}\text { Geremia et al. (2020) } \\
\text { Qualitativo } \\
\text { Enfermagem em Foco } \\
\text { Brasil } \\
\text { Infecções por } \\
\text { Coronavirus; } \\
\text { Pandemias; Sistema } \\
\text { Único de Saúde; } \\
\text { Serviços de Integração } \\
\text { Docente-Assistencial; } \\
\text { Educação em } \\
\text { Enfermagem. }\end{array}$ & $\begin{array}{l}\text { Estudo analítico } \\
12 \text { enfermeiras gestoras } \\
\text { Entrevista }\end{array}$ & $\begin{array}{l}\text { Cenário de desvalorização da enfermagem } \\
\text { no Brasil, em que se evidenciam } \\
\text { problemas estruturais na gestão do } \\
\text { trabalho no SUS e sua influência no } \\
\text { cenário de atuação da profissão. }\end{array}$ & $\begin{array}{l}\text { Para além das longas jornadas e baixa } \\
\text { remuneração, os profissionais de } \\
\text { enfermagem enfrentam problemas } \\
\text { decorrentes da exposição ao SARS-CoV-2, } \\
\text { falta de infraestrutura e de EPI. }\end{array}$ & $\begin{array}{l}\text { As tragédias podem representar } \\
\text { oportunidades, e na conjuntura da } \\
\text { COVID-19, reside a expectativa que } \\
\text { os profissionais da enfermagem } \\
\text { sejam respeitados financeira, } \\
\text { ética e profissionalmente; que os } \\
\text { governantes, os gestores e a sociedade, } \\
\text { compreendam a essencialidade do } \\
\text { trabalho desempenhado pela equipe } \\
\text { de enfermagem no cuidado em saúde e } \\
\text { na expansão do acesso aos serviços de } \\
\text { saúde. }\end{array}$ \\
\hline
\end{tabular}


Quadro 2. Síntese descritiva dos estudos incluídos (continuação)

\begin{tabular}{|c|c|c|c|c|}
\hline \multirow{2}{*}{$\begin{array}{l}\text { Autor/ Ano / Tipo de } \\
\text { estudo / Revista / Pais } \\
\text { / Palavras-Chave }\end{array}$} & \multicolumn{4}{|c|}{ Resultados } \\
\hline & $\begin{array}{c}\text { Metodologia (Amostra, tipo de estudo e } \\
\text { instrumento utilizado) }\end{array}$ & Papel da enfermagem & Desafios enfrentados & $\begin{array}{l}\text { Implicações para as práticas de } \\
\text { Enfermagem }\end{array}$ \\
\hline $\begin{array}{l}\text { Renke et al. (2020) } \\
\text { Qualitativo } \\
\text { Journal of Pediatric } \\
\text { Health Care } \\
\text { Estados Unidos } \\
\text { Pandemia de } \\
\text { COVID-19, enfermeira } \\
\text { pediatra, prática } \\
\text { avançadaprovedor, } \\
\text { âmbito da prática, } \\
\text { cuidados intensivos }\end{array}$ & $\begin{array}{l}\text { Estudo de Caso } \\
\text { Descritivo }\end{array}$ & $\begin{array}{l}\text { O foco da equipe se expandiu para além } \\
\text { do atendimento ao paciente individual } \\
\text { para incluir a saúde global geral. Os } \\
\text { esforços para limitar a exposição do } \\
\text { provedor e preservar o EPI alteraram } \\
\text { o fluxo de atendimento ao paciente e } \\
\text { exigiram métodos de comunicação não } \\
\text { convencionais quando a comunicação face } \\
\text { a face não era possível. }\end{array}$ & $\begin{array}{l}\text { A pandemia COVID-19 sobrecarregou } \\
\text { a infraestrutura de saúde, revelando } \\
\text { imperfeições no sistema médico e a } \\
\text { escassez de todos os recursos necessários } \\
\text { para o atendimento ao paciente. }\end{array}$ & $\begin{array}{l}\text { As equipes de cuidados da UTI do } \\
\text { COVID-19 eram multidisciplinares e } \\
\text { compostas por membros de diversas } \\
\text { origens e experiências. Funções e } \\
\text { responsabilidades padronizadas foram } \\
\text { desenvolvidas para apoiar a equipe em } \\
\text { um ambiente de processos de trabalho } \\
\text { e padrões de atendimento em rápida } \\
\text { mudança, com atenção especial à } \\
\text { segurança da equipe. Reconhecendo a } \\
\text { potencial escassez de pessoal, as equipes } \\
\text { de provedores foram organizadas usando } \\
\text { um híbrido de uma estratégia de pessoal } \\
\text { em camadas adaptada pela Society of } \\
\text { Critical Care Medicine. Nesse modelo, a } \\
\text { escassez de intensivistas adultos requer } \\
\text { o apoio de outros médicos e APPs para } \\
\text { atender às necessidades de cuidado do } \\
\text { paciente. }\end{array}$ \\
\hline $\begin{array}{l}\text { Stucky et al. (2020) } \\
\text { Qualitativo } \\
\text { Journal of } \\
\text { PeriAnesthesia Nursing } \\
\text { Estados Unidos } \\
\text { COVID-19; } \\
\text { Perioperatório; } \\
\text { Perianestesia; } \\
\text { Enfermagem; } \\
\text { Pandemia; Militares }\end{array}$ & $\begin{array}{l}\text { Relato de experiência } \\
\text { Estudo descritivo }\end{array}$ & $\begin{array}{l}\text { Os enfermeiros têm historicamente } \\
\text { liderado esforços para melhorar a saúde } \\
\text { das populações, ao mesmo tempo que } \\
\text { prestam cuidados de forma simultânea } \\
\text { e altruísta em momentos cruciais de } \\
\text { necessidade nacional. Enfermeiros } \\
\text { perioperatórios e perianestésicos } \\
\text { são vitais para a viabilidade geral de } \\
\text { enfermagem do sistema de saúde. }\end{array}$ & & $\begin{array}{l}\text { Novos modelos de equipe de UTI podem } \\
\text { ser necessários para garantir que todos } \\
\text { os pacientes recebam os cuidados } \\
\text { necessários. A Society of Critical Care } \\
\text { Medicine recomenda uma estratégia } \\
\text { de pessoal em camadas, em que os } \\
\text { enfermeiros não-UTI trabalham em pares } \\
\text { ou equipes com médicos experientes. }\end{array}$ \\
\hline
\end{tabular}


Quadro 2. Síntese descritiva dos estudos incluídos (continuação)

\begin{tabular}{|c|c|c|c|c|}
\hline \multirow{2}{*}{$\begin{array}{c}\text { Autor/ Ano / Tipo de } \\
\text { estudo / Revista / Pais } \\
\text { / Palavras-Chave }\end{array}$} & \multicolumn{4}{|c|}{ Resultados } \\
\hline & $\begin{array}{l}\text { Metodologia (Amostra, tipo de estudo e } \\
\text { instrumento utilizado) }\end{array}$ & Papel da enfermagem & Desafios enfrentados & $\begin{array}{l}\text { Implicações para as práticas de } \\
\text { Enfermagem }\end{array}$ \\
\hline $\begin{array}{l}\text { Monica et al. (2020) } \\
\text { Qualitativo } \\
\text { Infection, Disease \& } \\
\text { Health } \\
\text { Singapura } \\
\text { Surto pandémico; } \\
\text { Prática de prevenção de } \\
\text { infecções; Enfermagem } \\
\text { de controle de infecção; } \\
\text { Força-tarefa de } \\
\text { enfermagem }\end{array}$ & $\begin{array}{l}\text { Relato de Caso } \\
\text { Estudo descritivo }\end{array}$ & $\begin{array}{l}\text { Os enfermeiros desempenham um papel } \\
\text { vital antes e durante as pandemias, com } \\
\text { os enfermeiros líderes assumindo a } \\
\text { liderança na preparação para os surtos. }\end{array}$ & - & $\begin{array}{l}\text { Em resposta a um surto, o } \\
\text { reconhecimento precoce e a preparação } \\
\text { para a ameaça crescente, gerenciar os } \\
\text { desafios de pessoal juntamente com } \\
\text { o bem-estar dos enfermeiros são de } \\
\text { extrema importância. Estratégias para } \\
\text { promover o distanciamento físico sem } \\
\text { comprometer a educação continuada } \\
\text { de enfermagem e o cuidado ao paciente } \\
\text { também são essenciais. }\end{array}$ \\
\hline $\begin{array}{l}\text { Chen et al. (2020) } \\
\text { Qualitativo } \\
\text { Journal of } \\
\text { PeriAnesthesia Nursing } \\
\text { China } \\
\text { Enfermeira de } \\
\text { anestesia; Doença } \\
\text { do coronavírus 2019; } \\
\text { Equipe de resgate } \\
\text { médico }\end{array}$ & $\begin{array}{l}\text { Relato de experiência } \\
\text { Estudo descritivo }\end{array}$ & $\begin{array}{l}\text { O enfermeiro de anestesia possui } \\
\text { especialidades profissionais próprias, } \\
\text { como o manejo das vias aéreas, o uso e } \\
\text { manutenção de equipamentos de suporte } \\
\text { à vida, incluindo ventiladores, e o uso de } \\
\text { equipamentos de oxigênio de alto fluxo. } \\
\text { Com rica experiência em respostas de } \\
\text { emergência e enfermagem, enfermeiros } \\
\text { anestesistas, juntamente com enfermeiros } \\
\text { de emergência e enfermeiros de cuidados } \\
\text { intensivos, desempenham papéis } \\
\text { importantes durante o tratamento de } \\
\text { pacientes com CovID-19. }\end{array}$ & $\begin{array}{l}\text { O transporte de pacientes críticos } \\
\text { é um procedimento de alto risco. É } \\
\text { um desafio garantir a segurança de } \\
\text { pacientes criticamente enfermos durante } \\
\text { o transporte. Durante a epidemia de } \\
\text { síndrome respiratória aguda grave em } \\
\text { 2003, a proteção pessoal foi a principal } \\
\text { fonte de estresse para os enfermeiros. [...] } \\
\text { os enfermeiros não familiarizados com } \\
\text { o isolamento, a proteção e os cuidados } \\
\text { intensivos estão sujeitos ao estresse } \\
\text { mental, esgotamento físico e até mesmo } \\
\text { outras complicações. O enfermeiro da } \\
\text { anestesia trabalha rotineiramente em } \\
\text { centro cirúrgico e, portanto, pode não } \\
\text { ter experiência nos procedimentos de } \\
\text { enfermagem em enfermarias regulares e } \\
\text { na comunicação com o paciente, que são } \\
\text { duas deficiências. }\end{array}$ & $\begin{array}{l}\text { Os cuidados de anestesia por enfermeiras } \\
\text { são relativamente novos na China, e } \\
\text { o papel dos enfermeiros anestesistas } \\
\text { durante uma resposta a desastres não } \\
\text { foi totalmente apreciado. Espera-se que } \\
\text { as autoridades considerem a inclusão } \\
\text { de enfermeiras anestesistas nas equipes } \\
\text { nacionais de resgate médico de resposta } \\
\text { a desastres. }\end{array}$ \\
\hline
\end{tabular}


Quadro 2. Síntese descritiva dos estudos incluídos (continuação)

\begin{tabular}{|c|c|c|c|c|}
\hline \multirow{2}{*}{$\begin{array}{c}\text { Autor/ Ano / Tipo de } \\
\text { estudo / Revista / Pais } \\
\text { / Palavras-Chave }\end{array}$} & \multicolumn{4}{|c|}{ Resultados } \\
\hline & $\begin{array}{l}\text { Metodologia (Amostra, tipo de estudo e } \\
\text { instrumento utilizado) }\end{array}$ & Papel da enfermagem & Desafios enfrentados & $\begin{array}{l}\text { Implicações para as práticas de } \\
\text { Enfermagem }\end{array}$ \\
\hline $\begin{array}{l}\text { Wu et al. (2020) } \\
\text { Qualitativo } \\
\text { Annals of Global Health } \\
\text { China } \\
\text { Surto pandémico; } \\
\text { Prática de prevenção de } \\
\text { infecções; Enfermagem } \\
\text { de controle de infecção; } \\
\text { Força-tarefa }\end{array}$ & $\begin{array}{l}\text { Relato de experiência sobre a } \\
\text { realização de uma série de medidas de } \\
\text { gerenciamento de enfermagem na fase } \\
\text { estratégica e na fase de implementação. }\end{array}$ & $\begin{array}{l}\text { Por meio de uma série de medidas de } \\
\text { gerenciamento de enfermagem, todos } \\
\text { os pacientes COVID-19 internados } \\
\text { em nosso hospital foram curados e } \\
\text { receberam alta. Todos os pacientes não } \\
\text { COVID-19 e funcionários hospitalizados } \\
\text { durante o mesmo período não estavam } \\
\text { infectados com o vírus. Durante este } \\
\text { período, nosso hospital completou } 7.466 \\
\text { operações. Portanto, nossas medidas de } \\
\text { gerenciamento de enfermagem foram } \\
\text { eficazes. }\end{array}$ & $\begin{array}{l}\text { Devido à rápida propagação da } \\
\text { pandemia, pode haver uma escassez } \\
\text { no fornecimento de equipamentos de } \\
\text { proteção que não eram usados com } \\
\text { frequência no passado, especialmente } \\
\text { equipamentos de proteção médica } \\
\text { pessoal, como aventais, óculos de } \\
\text { proteção, máscaras N95 e semelhantes. }\end{array}$ & $\begin{array}{l}\text { O uso da Internet para comunicar nossa } \\
\text { mensagem a todos os enfermeiros e } \\
\text { realizar treinamentos remotos foi uma } \\
\text { novidade para nós e desempenhou } \\
\text { um papel tremendo em equipar todo o } \\
\text { pessoal com conhecimentos relevantes } \\
\text { para o combate à doença. }\end{array}$ \\
\hline $\begin{array}{l}\text { Chamboredon, Roman e } \\
\text { Colson (2020) } \\
\text { Qualitativo } \\
\text { International Nursing } \\
\text { Review } \\
\text { França } \\
\text { COVID-19, França, } \\
\text { Emergência de saúde, } \\
\text { Política de saúde, } \\
\text { Política de enfermagem } \\
\text { de enfermagem, } \\
\text { Enfermagem de } \\
\text { cuidados primários } \\
\text { para pandemias, Saúde } \\
\text { pública, Funções e } \\
\text { responsabilidades }\end{array}$ & $\begin{array}{l}\text { Relato de experiência } \\
\text { Estudo descritivo }\end{array}$ & $\begin{array}{l}\text { Hospitais e serviços de atenção primária, } \\
\text { com investimento significativo por } \\
\text { enfermeiros, desempenharam um papel } \\
\text { fundamental no cuidado de pessoas com } \\
\text { e sem COVID-19. }\end{array}$ & $\begin{array}{l}\text { A França deve gerenciar a primeira } \\
\text { onda da pandemia e, ao mesmo tempo, } \\
\text { empregar todos os meios para evitar } \\
\text { uma segunda onda. As políticas de saúde } \\
\text { devem então se adaptar a um vírus cuja } \\
\text { disseminação não é totalmente conhecida } \\
\text { e cujos tratamentos estão sendo } \\
\text { avaliados. }\end{array}$ & $\begin{array}{l}\text { As enfermeiras são reconhecidas por sua } \\
\text { utilidade social na França. No entanto, } \\
\text { é importante considerar os efeitos } \\
\text { colaterais dessa crise em enfermeiras e } \\
\text { enfermagem e integrar as habilidades } \\
\text { de enfermagem de emergência de saúde } \\
\text { estabelecidas durante a pandemia } \\
\text { no campo padrão de competência de } \\
\text { enfermagem. A profissão de enfermagem } \\
\text { espera uma reflexão e revisão das } \\
\text { competências do enfermeiro, bem como } \\
\text { a sua valorização no sistema de saúde } \\
\text { francês, nomeadamente levada a cabo } \\
\text { pela Ordem dos Enfermeiros do Conselho } \\
\text { Nacional da França. Uso do telecuidado } \\
\text { em enfermagem. }\end{array}$ \\
\hline
\end{tabular}


Quadro 2. Síntese descritiva dos estudos incluídos (conclusão)

\begin{tabular}{|c|c|c|c|c|}
\hline \multirow{2}{*}{$\begin{array}{l}\text { Autor/ Ano / Tipo de } \\
\text { estudo / Revista / Pais } \\
\text { / Palavras-Chave }\end{array}$} & \multicolumn{4}{|c|}{ Resultados } \\
\hline & $\begin{array}{l}\text { Metodologia (Amostra, tipo de estudo e } \\
\text { instrumento utilizado) }\end{array}$ & Papel da enfermagem & Desafios enfrentados & $\begin{array}{l}\text { Implicações para as práticas de } \\
\text { Enfermagem }\end{array}$ \\
\hline $\begin{array}{l}\text { Ridley, Freeman- } \\
\text { Sanderson e Haine } \\
\text { (2020) } \\
\text { Qualitativo } \\
\text { Australian Critical Care } \\
\text { Austrália } \\
\text { Trabalhadores; } \\
\text { Pandemia; Saúde aliada; } \\
\text { Doença do coronavírus; } \\
\text { Capacidade de surto; } \\
\text { Modelos de cuidado }\end{array}$ & $\begin{array}{l}\text { Relato de experiência } \\
\text { Estudo descritivo }\end{array}$ & $\begin{array}{l}\text { Os profissionais de saúde especializados } \\
\text { em cuidados intensivos há muito são } \\
\text { reconhecidos como uma força de trabalho } \\
\text { fundamental incorporada nas unidades de } \\
\text { terapia intensiva (UTIs) australianas, onde, } \\
\text { junto com a medicina e a enfermagem, } \\
\text { cuidam de alguns dos pacientes mais } \\
\text { enfermos dos hospitais }\end{array}$ & $\begin{array}{l}\text { Uma das principais limitações do } \\
\text { planejamento de pandemia na Austrália } \\
\text { durante o COVID-19 é a falta geral de } \\
\text { dados disponíveis sobre a capacidade de } \\
\text { trabalho do profissional especializado } \\
\text { em cuidados intensivos e a subsequente } \\
\text { resposta ao surto disponível na Austrália. }\end{array}$ & $\begin{array}{l}\text { O planejamento e a preparação da força } \\
\text { de trabalho de saúde aliada durante o } \\
\text { COVID-19 devem ser considerados ao se } \\
\text { considerar o atendimento ao paciente } \\
\text { abrangente e baseado em evidências. }\end{array}$ \\
\hline
\end{tabular}


Figura 2. Fluxograma de busca dos artigos da revisão sistemática e critérios de seleção

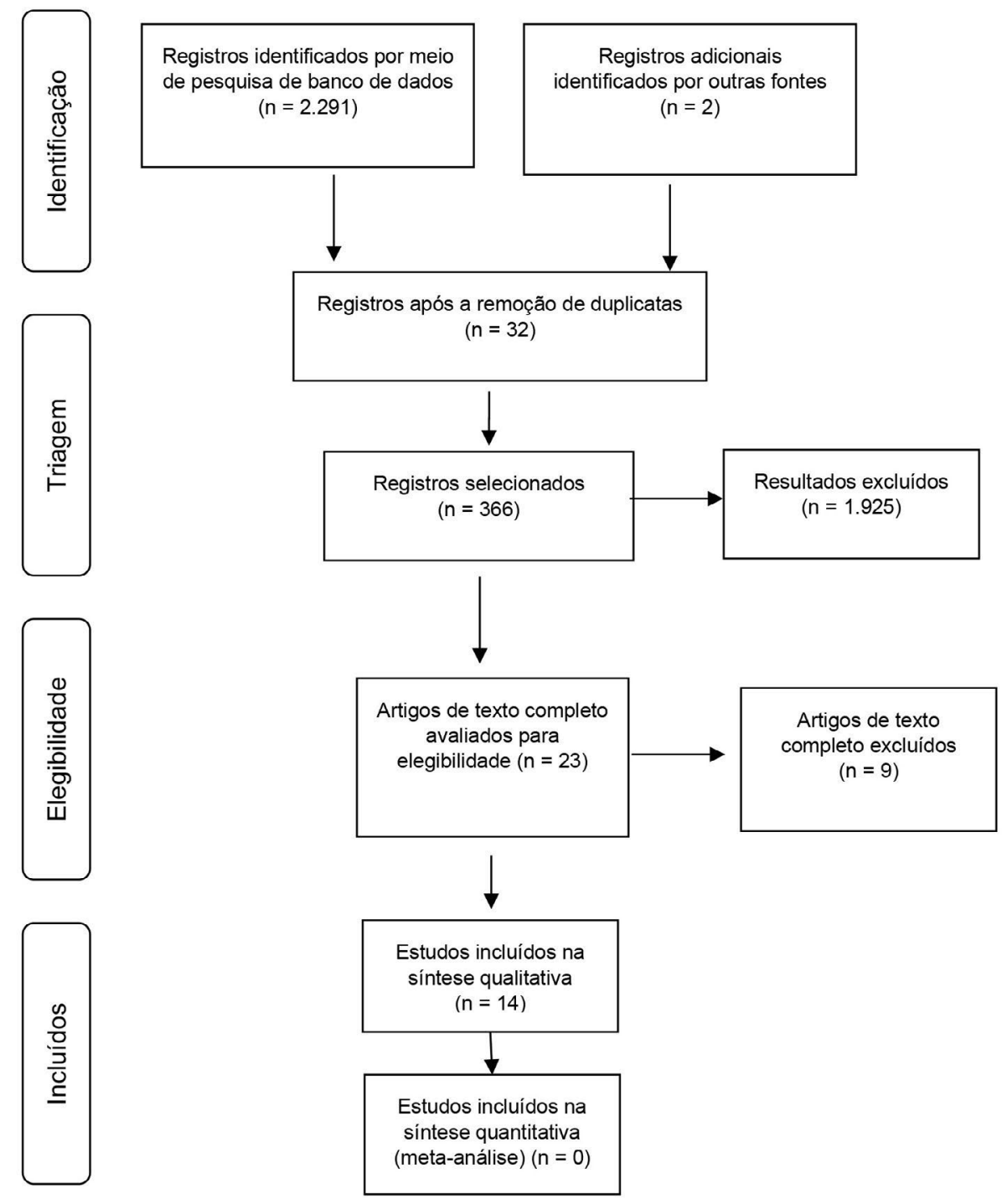


As pesquisas no Brasil em relação à atuação dos profissionais de enfermagem, a forma de trabalho e os legados deixados pela pandemia em relação às práticas da profissão na UTI ainda são escassas, mas ainda assim mostraram-se como maioria neste estudo, sendo 5 delas realizadas no país, as demais foram realizadas 1 no Taiwan, 1 na Suíça, 2 nos Estados Unidos, 1 em Singapura, 2 na China, 1 na França e 1 na Austrália. Todos os artigos brasileiros foram publicados na Revista Enfermagem em Foco.

Todos os artigos selecionados foram publicados no ano de 2020, verificando-se uma abordagem recente do assunto, mesmo com casos na China desde 2019, podendo-se dizer que as primeiras pesquisas estiveram focadas em melhor compreender a disseminação, prevalência e tratamento.

Quanto ao fator de impacto (tabela 1), os dados médios são 2.034, 4.285, 1.987, 1.615, 805, 2.577, 2.037 e 2.214 verificando como a revista de maior fator impacto a Enfermagem em Foco.

Tabela 1. Distribuição dos resultados dos estudos selecionados segundo autor, título e fator de impacto. Fortaleza - CE, Brasil, 2020

\begin{tabular}{|c|c|c|}
\hline Nomes dos Autores & Título dos Artigos & $\begin{array}{l}\text { Fator de } \\
\text { Impacto }\end{array}$ \\
\hline $\begin{array}{l}\text { Huang et al. }(2020)^{\text {ref }} \\
8\end{array}$ & $\begin{array}{l}\text { Roles of nurses and National Nurses Associations in combating COVID- } \\
\text { 19: Taiwan experience }\end{array}$ & 2.034 \\
\hline McDonald (2020) ${ }^{\text {ref } 9}$ & $\begin{array}{l}\text { Getting the COVID-19 pandemic into perspective: a nursing } \\
\text { Imperative }\end{array}$ & 2.034 \\
\hline $\begin{array}{l}\text { Nascimento, Hattori } \\
\text { e Terças-Trettel } \\
(2020)^{\text {ref } 10}\end{array}$ & $\begin{array}{l}\text { Dificultades y temores de las enfermeras que enfrentan la pandemia } \\
\text { de COVID-19 en Brasil }\end{array}$ & 4285 \\
\hline $\begin{array}{l}\text { Nascimento, Hattori } \\
\text { e Terças-Trettel } \\
(2020)^{\text {ref } 11}\end{array}$ & $\begin{array}{l}\text { Necessidades pessoais dos enfermeiros durante a pandemia da } \\
\text { COVID-19 em Mato Grosso }\end{array}$ & 4285 \\
\hline Silva et al. (2020) ref 12 & Protagonismo da Enfermagem Brasileira no combate ao COVID-19. & 4285 \\
\hline $\begin{array}{l}\text { Rodrigues et al. } \\
(2020)^{\text {ref } 13}\end{array}$ & $\begin{array}{l}\text { Gestão da pandemia Coronavírus em um hospital: relato de } \\
\text { experiência profissional. }\end{array}$ & 1987 \\
\hline $\begin{array}{l}\text { Geremia et al. (2020) } \\
\text { ref } 14\end{array}$ & $\begin{array}{l}\text { Pandemia COVID-2019: Formação e atuação da enfermagem para o } \\
\text { sistema único de saúde }\end{array}$ & 4285 \\
\hline $\begin{array}{l}\text { Renke et al. (2020) } \\
15\end{array}$ & $\begin{array}{l}\text { Utilization of Pediatric Nurse Practitioners as Adult Critical Care } \\
\text { Providers During the COVID-19 Pandemic: A Novel Approach }\end{array}$ & 1615 \\
\hline $\begin{array}{l}\text { Stucky et al. (2020) ref } \\
16\end{array}$ & $\begin{array}{l}\text { COVID-19: Initial Perioperative and Perianesthesia Nursing Response in } \\
\text { a Military Medical Center }\end{array}$ & 0805 \\
\hline $\begin{array}{l}\text { Monica et al. (2020) } \\
\text { ref } 17\end{array}$ & $\begin{array}{l}\text { Preparation and response to COVID-19 outbreak in Singapore: A case } \\
\text { report }\end{array}$ & 2577 \\
\hline Chen et al. (2020) ${ }^{\text {ref } 18}$ & $\begin{array}{l}\text { Role of Anesthesia Nurses in the Treatment and Management of } \\
\text { Patients With COVID-19 }\end{array}$ & 0805 \\
\hline Wu et al. (2020) ref 19 & $\begin{array}{l}\text { Contingency Nursing Management in Designated Hospitals During } \\
\text { COVID-19 Outbreak }\end{array}$ & 2.037 \\
\hline $\begin{array}{l}\text { Chamboredon, } \\
\text { Roman e Colson } \\
(2020)^{\text {ref } 20}\end{array}$ & $\begin{array}{l}\text { COVID-19 pandemic in France: health emergency experiences from the } \\
\text { field }\end{array}$ & 2.034 \\
\hline $\begin{array}{l}\text { Ridley, Freeman- } \\
\text { Sanderson e Haine } \\
(2020)^{\text {ref } 21}\end{array}$ & $\begin{array}{l}\text { Surge capacity for critical care specialised allied health professionals in } \\
\text { Australia during COVID-19 }\end{array}$ & 2.214 \\
\hline
\end{tabular}

Os artigos selecionados nesta pesquisa também foram analisados com base no JBI Critical Appraisal Checklist for Studies Reporting Prevalence Data. A tabela 2 apresenta esses resultados. 
Tabela 2. Avaliação das principais falhas dos artigos com base no JBI Critical Appraisal Checklist for Studies Reporting Prevalence Data. Fortaleza - CE, Brasil (2020)

\begin{tabular}{|c|c|c|c|c|c|c|c|c|c|c|c|c|}
\hline Autor, ano & Q1 & Q2 & Q3 & Q4 & Q5 & Q6 & Q7 & Q8 & Q9 & Q10 & Total & $\begin{array}{c}\text { Risco } \\
\text { de } \\
\text { Viés }\end{array}$ \\
\hline $\begin{array}{l}\text { Huang et al. } \\
(2020)^{\text {ref } 8}\end{array}$ & NA & NA & NA & NA & Sim & Sim & NA & NA & Sim & Sim & $100 \%$ & $\begin{array}{l}\text { Baixo } \\
\text { risco }\end{array}$ \\
\hline $\begin{array}{l}\text { McDonald (2020) } \\
\text { ref } 9\end{array}$ & NA & NA & NA & NA & Sim & Sim & NA & NA & Sim & Sim & $100 \%$ & $\begin{array}{l}\text { Baixo } \\
\text { risco }\end{array}$ \\
\hline $\begin{array}{l}\text { Nascimento, } \\
\text { Hattori e Terças- } \\
\text { Trettel }(2020)^{\text {ref }} \\
10\end{array}$ & Sim & Sim & Sim & Sim & Sim & $\operatorname{sim}$ & Não & Sim & $\operatorname{sim}$ & Sim & $90 \%$ & $\begin{array}{l}\text { Baixo } \\
\text { risco }\end{array}$ \\
\hline $\begin{array}{l}\text { Nascimento, } \\
\text { Hattori e Terças- } \\
\text { Trettel }(2020)^{\text {ref } 11}\end{array}$ & Sim & Sim & Sim & Sim & Sim & Sim & Não & Sim & Sim & Sim & $90 \%$ & $\begin{array}{l}\text { Baixo } \\
\text { risco }\end{array}$ \\
\hline $\begin{array}{l}\text { Silva et al. (2020) } \\
\text { ref } 12\end{array}$ & NA & NA & NA & NA & Sim & Sim & NA & NA & Sim & Sim & $100 \%$ & $\begin{array}{l}\text { Baixo } \\
\text { risco }\end{array}$ \\
\hline $\begin{array}{l}\text { Rodrigues et al. } \\
(2020)^{\text {ref } 13}\end{array}$ & NA & NA & NA & NA & Sim & Sim & NA & NA & Sim & Sim & $100 \%$ & $\begin{array}{l}\text { Baixo } \\
\text { risco }\end{array}$ \\
\hline $\begin{array}{l}\text { Geremia et al. } \\
(2020)^{\text {ref } 14}\end{array}$ & Sim & Sim & Sim & Sim & Sim & Sim & Não & NA & NA & NA & $90 \%$ & $\begin{array}{l}\text { Baixo } \\
\text { risco }\end{array}$ \\
\hline $\begin{array}{l}\text { Renke et al. } \\
(2020)^{\text {ref } 15}\end{array}$ & NA & NA & NA & NA & Sim & Sim & NA & NA & Sim & Sim & $100 \%$ & $\begin{array}{l}\text { Baixo } \\
\text { risco }\end{array}$ \\
\hline $\begin{array}{l}\text { Stucky et al. } \\
(2020)^{\text {ref } 16}\end{array}$ & NA & NA & NA & NA & Sim & Sim & NA & NA & Sim & Sim & $100 \%$ & $\begin{array}{l}\text { Baixo } \\
\text { risco }\end{array}$ \\
\hline $\begin{array}{l}\text { Monica et al. } \\
(2020)^{\text {ref } 17}\end{array}$ & NA & Sim & NA & NA & Sim & Sim & NA & NA & Sim & Sim & $100 \%$ & $\begin{array}{l}\text { Baixo } \\
\text { risco }\end{array}$ \\
\hline $\begin{array}{l}\text { Chen et al. (2020) } \\
\text { ref } 18\end{array}$ & NA & Sim & NA & NA & $\operatorname{Sim}$ & Sim & NA & NA & Sim & Sim & $100 \%$ & $\begin{array}{l}\text { Baixo } \\
\text { risco }\end{array}$ \\
\hline $\begin{array}{l}\text { Wu et al. }(2020)^{\text {ref }} \\
19\end{array}$ & NA & Sim & NA & NA & Sim & $\operatorname{sim}$ & NA & NA & Sim & Sim & $100 \%$ & $\begin{array}{l}\text { Baixo } \\
\text { risco }\end{array}$ \\
\hline $\begin{array}{l}\text { Chamboredon, } \\
\text { Roman e Colson } \\
(2020)^{\text {ref } 20}\end{array}$ & NA & Sim & NA & NA & Sim & Sim & NA & NA & Sim & Sim & $100 \%$ & $\begin{array}{l}\text { Baixo } \\
\text { risco }\end{array}$ \\
\hline $\begin{array}{l}\text { Ridley, Freeman- } \\
\text { Sanderson e } \\
\text { Haine }(2020)^{\text {ref } 21}\end{array}$ & NA & NA & NA & NA & Sim & Sim & NA & NA & Sim & Sim & $100 \%$ & $\begin{array}{l}\text { Baixo } \\
\text { risco }\end{array}$ \\
\hline \multicolumn{13}{|c|}{$\begin{array}{l}\text { NA: Não se Aplica } \\
\text { Legenda: Q1. O quadro da amostra foi apropriado para abordar a população-alvo? Q2. Os participantes do estudo } \\
\text { foram amostrados de maneira apropriada? Q3. O tamanho da amostra foi adequado? Q4- As características dos } \\
\text { sujeitos do estudo foram descritas em detalhes? Q5- A análise dos dados foi conduzida com suficiente cobertura da } \\
\text { amostraidentificada? Q6- A mensuração da condição foi objetiva e com critérios padronizados? Q7- A condição foi } \\
\text { mensurada de forma confiável? Q8- A análise estatística usada foi apropriada? Q9- Todos os fatores de } \\
\text { confundimento importantes/ subgrupos/ diferenças foram identificados e contabilizados? Q10- As subpopulações } \\
\text { foram identificadas usando critérios objetivos? }\end{array}$} \\
\hline
\end{tabular}

Como é possível verificar na tabela 2, todos os artigos apresentaram baixo risco de viés, com questões referentes à amostragem e estatísticas não foram aplicáveis aos artigos que utilizaram como metodologia relato de experiência. Para aqueles que realizaram estudos exploratórios verificou-se falha somente na confiabilidade da condição de mensuração ${ }^{10,11,14}$. Em relação a todos os fatores de confundimento importantes/ subgrupos/ diferenças foram identificados e contabilizados todos os artigos atenderam a esse quesito.

Em relação aos resultados, verificou-se que a atuação do profissional de enfermagem no combate ao COVID-19 é consenso em diferentes países do mundo, sendo destacada sua atuação como linha de frente e as necessidades de adaptação a um contexto inédito, lidando com o desconhecido e com pesquisas frequentes que apontavam novas descobertas, precisando os profissionais prestarem os cuidados aos pacientes, ao mesmo tempo em que tomam os devidos cuidados para sua própria proteção. 
Os desafios e legados também convergiram entre os autores, independente do país de realização da pesquisa. Verificou-se que os cuidados dos próprios profissionais têm sido principalmente questões referentes à higienização e ao uso de equipamentos de proteção individual (EPI), com os ensinamentos de Florence Nightingale ficando mais atuais do que nunca nesse cenário. As adaptações desses profissionais também foram direcionadas pela necessidade de isolamento social, que exigiram criação de alas específicas para cuidados desses pacientes, assim como a criação de protocolos que pudessem atender pacientes críticos sem colocar-se em riscos, sendo provavelmente esse o seu maior desafio.

Como implicações futuras do atendimento em enfermagem frente à atual pandemia, verificou-se fatores como maior valorização dos profissionais de enfermagem, inclusive com uso de profissionais intensivistas e anestesistas nesses casos, diversificação das formas de comunicação, o melhor autogerenciamento e gerenciamento das equipes e o teleatendimento em cuidados de enfermagem.

Os artigos selecionados demonstraram a importância do papel dos enfermeiros como linha de frente no combate à COVID-19, verificando-se desafios e implicações futuras para o trabalho desses profissionais na Unidade de Terapia Intensiva (UTI).

\section{Protagonismo dos profissionais de enfermagem}

Silva et al. ${ }^{12}$ mencionam a importância dos profissionais de Enfermagem no Brasil, enquanto protagonistas no combate ao coronavírus. Os autores destacam os ensinamentos de Florence Nightingale como mais atuais do que nunca, dado que os cuidados básicos foram fundamentais para redução da disseminação da doença, como lavagem de mãos, limpeza de hospitais e ambientes domésticos. Salienta-se que, enquanto ciência, a enfermagem se ampara em um vasto leque de referenciais teóricos e teorias específicas de enfermagem que fundamentam as bases do cuidado. Este é concretizado a partir da Sistematização da Assistência de Enfermagem (SAE) nas instituições de saúde, hoje requisito obrigatório para a atuação da enfermagem e operacionalizado pelo Processo de Enfermagem (PE).

Segundo Fernandes ${ }^{22}$, o conceito de terapia intensiva surgiu no conflito da Criméia, quando Florence
Nightingale em Scutari (Turquia), onde a mesma atendeu, junto a 38 enfermeiras, soldados britânicos seriamente feridos, agrupados e isolados em áreas com medidas preventivas para evitar a disseminação de doenças como disenteria e tétano, sendo marcante a redução de mortalidade. Fernandes ${ }^{22}$ ressalta em suas observações que o objetivo principal das unidades de terapia intensiva (UTI) é manter uma estrutura capaz de fornecer suporte para pacientes graves, com potencial risco de morte.

Nesse mesmo sentido, Renke et al. ${ }^{15}$ destacam que a pandemia da COVID-19 evidenciou o colapso da saúde pública no mundo, principalmente pela escassez de recursos tanto materiais quanto humanos. A profissão de enfermagem demonstrou-se fundamental nesse ambiente, inclusive com remanejamento de enfermeiros pediátricos para o cuidado de adultos.

Chamboredon, Roman e Colson²0, em estudo realizado na França, também foram enfáticos ao destacar a importância dos profissionais de enfermagem durante a pandemia em tela, sendo mencionada a necessidade de maior reconhecimento desses profissionais. A pesquisa realizada pelos autores converge com os demais achados em relação à principal estratégia nos hospitais do país ser a aplicação de medidas de contaminação cruzada para prevenir a propagação do vírus, como boa higiene das mãos, evitando contato próximo com outras pessoas ou distanciamento social e respeitando as regras de higiene respiratória.

McDonald ${ }^{9}$ compartilha desse mesmo pensamento ao considerar a realidade de profissionais na Suíça, destacando o relevante papel no combate à COVID-19. A autora ainda menciona a importância dos enfermeiros na educação em saúde e na busca por garantir recursos e suprimentos para a população mais carente.

\section{Desafios enfrentados}

Nascimento, Hattori e Terças-Trettel 10 elucidam que no Brasil os profissionais de Enfermagem enfrentaram dificuldades semelhantes ao restante do mundo, destacando-se fatores relacionados ao risco diário de exposição ao vírus, problemas de acesso e uso de equipamentos de proteção individual, dúvidas no diagnóstico diferencial bem como a sobrecarga de trabalho e o aumento da demanda por atendimento de pacientes e familiares. 
Considerando a experiência de Taiwan, Huang et al. $\frac{8}{8}$ elucidam que apesar de haver muita preocupação em relação à adequação dos recursos e suprimentos médicos para atendimento aos pacientes, o número de enfermeiros é crítico, o que evidenciou a necessidade de um maior preparo das equipes tanto em número quanto em capacitação para lidar com situação de pandemia. Os autores citam que a resposta rápida e a alta vigilância da Central Epidemic Command Center (CECC) foram essenciais para conter a COVID-19.

McDonald9 acrescenta como desafio a falta de apoio de profissionais em posição de liderança em relação à obtenção de recursos e proteção da linha de frente ou mesmo avisos antecipados ou divulgação aberta sobre o risco de contágio, números de casos e resultados. Geremia et al. ${ }^{14}$, por sua vez, verificaram que o cenário ainda é desvalorização da enfermagem, sendo evidenciado sob o ponto de vista de enfermeiras gestoras, problemas estruturais na gestão do trabaIho no SUS. Os autores destacaram que a sobrecarga no trabalho das profissionais é um dos principais problemas somado à baixa remuneração, exposição ao vírus, falta de estrutura e de Equipamentos de Proteção Individual (EPI) para esses profissionais.

As dificuldades apontadas por Chamboredon, Roman e Colson ${ }^{20}$ se voltam para a necessidade de lidar com uma pandemia inédita, com um vírus desconhecido, onde não se sabe ao certo nem mesmo sua real forma de disseminação, além dos tratamentos mais adequados ainda estarem em análise, demandando de adaptações constantes, já que estudos estão sendo frequentemente realizados em busca de um resultado mais eficaz para tratamento, enquanto ainda se espera uma vacina que venha a de fato garantir a imunidade da população.

Em outra pesquisa realizada por Nascimento, Hattori e Terças-Trettel 11 foram evidenciadas necessidades pessoais dos enfermeiros do Mato Grosso - Brasil durante a pandemia, verificando que a situação de isolamento para reduzir o contágio por coronavírus foi um dos maiores desafios enfrentados por eles, surgindo quatro ideias centrais: autocuidado, necessidade, de afeto, compreensão do distanciamento e prejuízos na relação conjugal. Essa necessidade de adaptação dos profissionais também foi mencionada por Rodrigues et al. $\frac{13}{}$ que também mencionaram como um dos maiores desafios enfrentados por esses profissionais, citando atendimento ao paciente suspeito ou confirmado, carga horária de trabalho, paramentação, uso correto dos EPI e aumento da complexidade assistencial, vêm se mostrando como grandes preocupações.

\section{Legados da pandemia}

Em relação às implicações futuras trazidas pela prática na COVID-19, McDonald cita uma série de fatores, desde a percepção da necessidade de credibilidade das informações dos especialistas que devem ser concisas e claras sobre o que é conhecido e o que é incerto e como isso mudará com o tempo, até um maior controle da cadeia de suprimentos pela equipe de enfermagem e revisão nos modelos de pessoal para permitir que até $50 \%$ dos enfermeiros fiquem isolados ou em quarentena na maior parte do tempo.

De acordo com Nascimento, Hattori e Terças-Trettel ${ }^{10}$, é possível destacar como um legado do aprendizado prático trazido por essa pandemia um melhor autogerenciamento por parte do próprio profissional. Nesse sentido, Rodrigues et al. ${ }^{13}$ destacam os protocolos criados para adaptação às necessidades de isolamento para contenção do vírus, assim como a proteção dos profissionais e segurança dos pacientes. Como legado, Geremia et al. ${ }^{14}$ esperam que o cenário ocasionado pela COVID-19 proporcione uma maior valorização da profissão de enfermagem, considerando sua importância no combate ao coronavírus, compreendendose, assim, a essencialidade do seu trabalho.

Renke et al. ${ }^{15}$ elucidam que o legado deixado pela pandemia pode ser visto em diferentes esferas, desde a comunicação que exigiu métodos não convencionais até a reorganização de equipes com funções e responsabilidades padronizadas, com estratégias de pessoal em camadas para promover maior segurança dos profissionais e dos pacientes. Como a escassez de intensivistas para adultos e a necessidade de realocação de enfermeiros pediátricos para suprir a demanda.

Em relação aos profissionais especializados em cuidados intensivos, Ridley, Freeman-Sanderson e Haine ${ }^{21}$ em seu estudo realizado na Austrália destacaram a importância dos mesmos juntamente à equipe médica e aos demais profissionais de enfermagem, dados os conhecimentos específicos para lidar com pacientes críticos, sendo eles dotados de conhecimentos exclusivos que podem contribuir de forma significativa para o melhor gerenciamento dos pacientes na pandemia. 
Stucky et al. $\frac{16}{6}$ destacam como contribuições da pandemia COVID-19 a gestão e equipes, com novos modelos de equipes de UTI fazendo-se necessários para o atendimento da demanda, uma estratégia de pessoal em camadas, em que os enfermeiros não-UTI trabalham em pares ou equipes com médicos experientes. Os enfermeiros perioperatórios e perianestesistas podem atuar de forma significativa no atendimento aos pacientes com COVID-19, destacando-se entre suas funções: administração de medicamentos, monitoramento de resultados laboratoriais, fornecimento de nutrição enteral e fornecimento de atendimento psicossocial, liberando médicos de UTI qualificados para gerenciar vários pacientes que requerem ventilação mecânica avançada ou oxigenação por membrana extracorpórea.

No caso relatado por Monica et al. ${ }^{17}$, foram citadas as medidas tomadas Singapore General Hospital que, até agosto de 2020, não tiveram nenhum caso de contaminação de enfermeiros em suas instalações. Para alcançar esse resultado, Monica et al. ${ }^{17}$ afirmam que um posto de comando de enfermagem foi organizado para coordenar os esforços em diferentes unidades de enfermagem, o que garantiu comunicação precisa e oportuna, bem como disponibilidade de força de trabalho, equipamentos e suprimentos entre as unidades. Foram criadas também áreas adicionais adjacentes ao departamento de emergência com o intuito de abrigar pacientes com sinais de infecções respiratórias e área de isolamento para acomodar pacientes com COVID-19.

De acordo com Monica et al. $\frac{17}{}$, o distanciamento físico foi praticado desde o início, com os profissionais de enfermagem sendo divididos em equipes de cuidados menores para um grupo de pacientes. $O$ distanciamento foi praticado tanto entre funcionários quanto entre profissionais e pacientes e para que isso fosse possível foi necessária a utilização de tecnologias, com dispositivos conectados aos pacientes para que fosse possível o seu monitoramento remoto por meio de um aplicativo móvel.

Resultado semelhante foi apontado por Chamboredon, Roman e Colson²0, que destacaram o uso do telecuidado em enfermagem, que pode ser considerada como uma prática que provavelmente irá prosseguir em uso na pós-pandemia. Os autores descrevem o uso da estratégia afirmando que o contexto de saúde possibilitou a criação do primeiro procedimento de tele-atendimento relacionado ao manejo de pacientes com COVID-19 por enfermeiras domiciliares, desde que o paciente tivesse receita médica e garantisse a disponibilidade e domínio das ferramentas de tele-monitoramento (smartphone, computador com conexão Wi-Fi ou, em caso de falha isso, telefone). O serviço foi coberto pelo seguro de saúde francês e possibilitou o acompanhamento dos pacientes, reduzindo drasticamente a exposição ao risco de contaminação dos cuidadores.

Wu et al. ${ }^{19}$, também considerando a realidade de um hospital, nesse caso, na China, também apontaram as boas práticas de gerenciamento de enfermagem que possibilitaram resultados eficientes no atendimento dos pacientes e a proteção dos seus profissionais. Os autores descrevem a estratégia mencionando que em primeiro lugar foi mobilizada efetivamente toda a mão de obra disponível; em segundo lugar, pessoal qualificado e treinado dentro de um período de tempo muito curto; em terceiro lugar, foi fornecido apoio logístico confiável para equipamentos de proteção de linha de frente; e, finalmente, os enfermeiros foram motivados durante este período contribuir de forma significativa para a luta contra a pandemia COVID-19.

A comunicação entre os profissionais foi facilitada pelo uso da internet, assim como a chegada de novos conhecimentos aos mesmos. Salienta-se como uma inovação do atendimento o fato de ao invés de transferir pacientes gravemente enfermos para o departamento de terapia intensiva, o hospital maximizou o espaço para os pacientes com infecção COVID-19 buscarem tratamento centralmente e reduzir o fluxo de pacientes no hospital, com isso, também reduziu o consumo de recursos e custos hospitalares ${ }^{17,19,21}$.

Chen et al. ${ }^{18}$ consideram como um legado da crise trazida pela COVID-19 o maior aproveitamento de enfermeiros anestesistas para gerenciamento dos casos críticos, visto terem especialidades profissionais próprias, como o manejo das vias aéreas, o uso e manutenção de equipamentos de suporte à vida, incluindo ventiladores, e o uso de equipamentos de oxigênio de alto fluxo, fundamentais no manejo de pacientes com COVID-19. Todavia, como a rotina desses profissionais geralmente se limita aos centros cirúrgicos, faltandoIhes experiência em procedimentos de enfermagem regulares, assim como na comunicação com o paciente, fazendo-se necessário treinamento dos mesmos para que eles possam melhor atuar nos casos 
de crise ou formação de equipes que incluam enfermeiros de emergência e enfermeiros de cuidados intensivos. Assim, considerando os resultados obtidos em um hospital da China em relação ao atendimento de enfermeiros anestesistas no atendimento a pacientes com COVID-19, espera-se que esses profissionais sejam vistos e incluídos nas equipes de resgate médico de resposta a desastres.

Salienta-se que este estudo foi limitado pela escassez de pesquisas sobre o assunto, considerando ser um tema ainda recente, com uma pandemia ainda em curso, apesar de muitos estudiosos estarem se dedicando ao assunto, as pesquisas ainda se concentram na busca de tratamento, vacina e outras investigações sobre a doença em si, com o trabalho do profissional de enfermagem ainda não sendo uma preocupação central.

\section{Conclusão}

O estudo realizado demonstrou que a pandemia trazida pela COVID-19 tem evidenciado o protagonismo dos profissionais de enfermagem. As pesquisas realizadas em diferentes países convergiram em relatar a importância dos profissionais na prevenção e combate à doença. Com as mudanças e adaptações necessárias ao atendimento dos pacientes e à proteção simultânea dos profissionais foram necessários novos protocolos e formas de atendimento podendo ser considerados como legados da atual pandemia, esperando-se maior valorização desses profissionais tanto pela população quanto pelos entes governamentais.

\section{Contribuições das autoras}

Bandeira FLF e Melo KAS participaram da interpretação dos resultados finais do manuscrito. Silva PS discutiu os resultados encontrados. Pinho MAB e Andrade JMF participaram da escrita do manuscrito. Ribeiro JF foi responsável pela idealização, planejamento, revisões do manuscrito e aprovação da versão final.

\section{Conflitos de interesses}

Nenhum conflito financeiro, legal ou político envolvendo terceiros (governo, empresas e fundações privadas, etc.) foi declarado para nenhum aspecto do trabalho submetido (incluindo, mas não se limitando a subvenções e financiamentos, participação em conselho consultivo, desenho de estudo, preparação de manuscrito, análise estatística, etc.).

\section{Referências}

1. Organização Mundial de Saúde. Folha informativa COVID-19 - Escritório da OPAS e da OMS no Brasil [Internet]. 2020. [citado em 2020 set 05]. Disponível em: https://www.paho.org/pt/ covid19\#: :text=Em\%2011\%20de\%20mar\%C3\%A70\%20de,8\%20 de $\% 20$ setembro\%20de $\% 202020$

2. Polakiewicz R. Saúde mental de profissionais de enfermagem na pandemia de coronavírus [Internet]. Portal PebMed; 2020. [citado em 2020 set 05]. Disponível em: https://pebmed.com.br/ saude-mental-de-profissionais-de-enfermagem-na-pandemia-decoronavirus/

3. Ministério da Saúde (Brasil), Secretaria de Vigilância em Saúde. Boletim Epidemiológico Especial 21: Doença pelo Coronavírus COVID-19 [Internet]. Brasília: Ministério da Saúde / Secretaria de Vigilância em Saúde. 2020. [citado em 2020 set 05]. Disponível em: http://saude.gov.br/images/pdf/2020/July/08/Boletimepidemiologico-COVID-21-corrigido-13h35.pdf

4. Bitencourt JVOV, Meschial WC, Frizon G, Biffi P, Souza JB, Maestri E. Protagonismo do enfermeiro na estruturação e gestão de uma unidade específica para COVID-19. Texto contexto - enferm. 2020;29: e20200213. http://dx.doi.org/10.1590/1980265x-tce-2020-0213

5. Barbosa DJ, Gomes MP, Souza FBA, Gomes AMT. Fatores de estresse nos profissionais de enfermagem no combate à pandemia da COVID-19: síntese de evidências. Com. Ciências Saúde [Internet]. 2020;31(suppl 1):31-47. Disponível em: http://www.escs.edu.br/revistaccs/index.php/ comunicacaoemcienciasdasaude/article/view/651

6. Prospero [Internet]. Reino Unido: Centre for Reviews and Dissemination, University of York. Disponível em: https://www.crd. york.ac.uk/PROSPERO/ 
7. Joanna Briggs Institute. Joanna Briggs Institute reviewers' manual: 2014 edition The Systematic Review of Prevalence and Incidence Data [Internet]. The University of Adelaide: The Joanna Briggs Institute: 2014. [citado em 2020 out 20]. Disponível em: https://nursing.Isuhsc.edu/JBI/docs/ReviewersManuals/ Prevalence-and-Incidence-Data.pdf

8. Huang LH, Chen CM, Chen SF, Wang HH. Roles of nurses and National Nurses Associations in combating COVID-19: Taiwan experience. Int nur rev. 2020;67(3):318-22. https://doi. org/10.1111/inr.12609

9. McDonald T. Getting the COVID-19 pandemic into perspective: a nursing imperative. Int nurs rev. 2020;67(3):305-17. https://doi. org/10.1111/inr.12608

10. Nascimento VF, Hattori TY, Terças-Trettel ACP. Dificultades y temores de las enfermeras que enfrentan la pandemia de COVID-19 en Brasil. Rev Hum Med [Internet]. 2020;20(2):31233. Disponível em: http://scielo.sld.cu/scielo.php?script=sci arttext\&pid=S1727-81202020000200312\&lng=es

11. Nascimento VF, Hattori TY, Terças-Trettel ACP. Necessidades pessoais de enfermeiros durante a pandemia da COVID-19 em Mato Grosso. Enferm. Foco [Internet]. 2020;11(1):141-5. Disponível em: http://biblioteca.cofen.gov.br/wp-content/ uploads/2020/09/necessidades-pessoais-enfermeiros-pandemiacovid-19-mato-grosso.pdf

12. Silva MCN, Cunha CLF, Ximenes Neto FRG, Santos JLG, Lourenção LG, Freire NP, et al. Protagonismo da Enfermagem Brasileira no combate ao COVID-19. Enferm. Foco [Internet]. 2020;11(1,n.esp):8-9. Disponível em: http://revista.cofen.gov.br/ index.php/enfermagem/article/view/4073/797

13. Rodrigues NH, Silva LGA. Gestão da pandemia Coronavírus em um hospital: relato de experiência profissional. J. Nurs. health. 2020;10(4):e20104004. https://doi.org/10.15210/jonah. v10i4.18530

14. Geremia DS, Vendruscolo C, Celuppi IC, Souza JB, Schopf K, Maestri E. Pandemia COVID-2019: formação e atuação da enfermagem para o Sistema Único de Saúde. Enferm. Foco [Internet]. 2020;11(1,n.esp):40-7. https://doi.org/10.21675/2357707X.2020.v11.n1.ESP.3956
15. Renke C, Callow L, Egnor T, Honstain C, Kellogg K, Pollack $B$, et al. Utilization of pediatric nurse practitioners as adult critical care providers during the COVID-19 pandemic: A novel approach. J Pediatr Health Care. 2020;34(5):490-4. https://dx.doi. org/10.1016\%2Fj.pedhc.2020.06.005

16. Stucky CH, De Jong MJ, Lowe AW, Mathews B. COVID-19: Initial Perioperative and Perianesthesia Nursing Response in a Military Medical Center. J Perianesth Nurs. 2020;35(4):353-6. https://doi. org/10.1016/j.jopan.2020.04.010

17. Monica FPE, Aloweni F, Yuh AS, Ayob EBM, Ahmad NB, Lan CJ, et al. Preparation and response to COVID-19 outbreak in Singapore: A case report. Infect Dis Health. 2020;25(3):216-8. https://doi.org/10.1016/j.idh.2020.04.002

18. Chen Q, Lan X, Zhao Z, Hu S, Tan F, Gui P, et al. Role of anesthesia nurses in the treatment and management of patients with COVID-19. J PeriAnesth Nurs. 2020;35(5):453-6. https://doi. org/10.1016/j.jopan.2020.05.007

19. Wu X, Zheng S, Huang J, Zheng Z, Xu M, Zhou Y. Contingency Nursing Management in Designated Hospitals During COVID-19 Outbreak. Ann Glob Health. 2020;86(1):70. http://doi.org/10.5334/ aogh.2918

20. Chamboredon P, Roman C, Colson S. COVID-19 pandemic in France: health emergency experiences from the field. Int Nurs Rev. 2020;67(3):326-33. https://doi.org/10.1111/inr.12604

21. Ridley EJ, Freeman-Sanderson A, Haines KJ. Surge capacity for critical care specialised allied health professionals in Australia during COVID-19. Aust Crit Care. 2020;34(2):191-3. https://doi. org/10.1016/j.aucc.2020.07.006

22. Fernandes HS, Silva E, Capone Neto A, Pimenta LA, Knobel E. Gestão em terapia intensiva: conceitos e inovações. Rev Bras Clin Med [Internet]. 2011;9(2):129-37. Disponível em: http://files.bvs. br/upload/S/1679-1010/2011/v9n2/a1829.pdf 